\title{
Geographical influence \\ on the radiation exposure of an aircrew on board a subsonic aircraft*
}

\author{
F. SPURNÝ**, I. VOTOČKOVÁA*, J.F. BOTTOLLIER-DEPOIS***
}

\author{
(Manuscrit reçu le 29 septembre 1995, révisé le 9 octobre 1995,
} accepté le 21 février 1996)

RÉSUMÉ Les champs de rayonnement à bord des avions subsoniques ont été étudiés au cours des vols Prague - Abu Dhabi - Bangkok et Bangkok - Abu Dhabi Prague, au mois de février 1995. Un ensemble complexe d'instruments de mesures a été utilisé : un compteur proportionnel équivalent au tissu, un remmètre de neutrons, un débitmètre pour l'environnement ; des détecteurs thermoluminescents, un détecteur solides de traces, et des détecteurs à bulles. Les résultats obtenus sont présentés et analysés ; ils sont confrontés aux résultats obtenus pendant une période proche au cours de vols Prague - Montréal Prague. Les conclusions concernent l'influence des paramètres géographiques sur le niveau d'irradiation du personnel navigant.

ABSTRACT Radiation fields on board a subsonic aircraft have been studied on board an airbus A310-300 during the flights Prague - Abu Dhabi - Bangkok and Bangkok - Abu Dhabi - Prague, during February 1995. A complex set of measuring instruments has been used for these studies: tissue equivalent proportional counter, moderator-type neutron rem-meter, environmental radiation dose rate meter, thermoluminescent and track etch detectors and bubble detectors. The results obtained are presented and analyzed; they are compared with the results obtained in the flights Prague - Montreal - Prague. Conclusions concerning the influence of geographical parameters on the aircrew exposure levels are formulated.

\section{Introduction}

ICRP 60 recommendations (1991) propose to decrease the annual limit of dose equivalent for the general public to $1 \mathrm{mSv}$. Many members of civil aircrafts regularly exceed this limit and the new document mentioned recommends to include them among occupational exposed workers. Many studies have been carried out since 1991 to improve the knowledge concerning the aircraft exposures (Reitz et al. Eds, 1993; Höfert and Stevenson, 1994; Spurný and Votočková, 1994).

* Studies partially supported through the EC project FI3P-CT92-0026.

** Department of Radiation Dosimetry, NPI AS CR, CZ 180 86, Praha 8, Czech Republic. *** Service de Dosimétrie, DPHD-IPSN-CEA, Centre d'Études Nucléaires de Fontenay-auxRoses, BP 6, F-92265 Fontenay-aux-Roses, France. 
This work presents and analyses the results of studies performed on board subsonic aircrafts during the flights Prague - Abu Dhabi - Bangkok, resp. Bangkok - Abu Dhabi - Prague. They are compared with results obtained during the flights Prague - Montreal, resp. Montreal - Prague, roughly in the same period (February 1995 for both). Conclusions concerning the influence of geographical parameters on the aircrew exposure levels are formulated.

\section{Experimental}

\subsection{Dosimeters used}

The dosimeter system used has been already described in our previous contribution concerning Prague - Montreal - Prague flights (Spurný et al., 1996). We will only remind that the following instruments or detectors have been used:

\section{Active measuring equipment}

- tissue equivalent proportional counter NAUSICAA (Nguyen et al., 1985; Bousset and Nguyen, 1992) to characterize the radiation with linear energy transfer between 0.15 and $1500 \mathrm{keV}$ per $\mu \mathrm{m}$; 1964);

- moderator type neutron dose equivalent meter NM2 (Anderson and Braun,

- a radiometer RP114 constructed on the base of GM counters to measure low LET radiation environmental dose rates (Radiometer RP114, 1992); and

- two types of individual electronic personal dosemeters based or on small Sidiode (Merlin Gerin, France), or on a small GM counter (ZMA Ostrov, Czech Republic).

\section{Passive detectors}

- thermoluminescent CaSO4:Dy detector produced in the laboratory (Guelev et al., 1994) to characterize the low LET component of radiation;

- track-etch detectors (CR39 of Pershore (Spurný et al., 1993)) to characterize neutron component; and

- bubble damage neutron detectors (BD100R and PND from BTI Chalk River) (Ing, 1991); with nominal sensitivities 1 bubble per $1 \mu \mathrm{Sv}\left(H^{*}(10)\right)$ of AmBe neutrons.

Low LET radiation measuring instruments have been calibrated by $60 \mathrm{Co}$ photons; high LET radiation measuring instruments have been calibrated using $252 \mathrm{Cf}$ neutrons. The responses has been always expressed in terms of ambient dose equivalent $H^{*}(10)$. 


\subsection{Flight routes studied}

Two on-board studies are presented and discussed in this work:

- the study performed during the flight Prague - Abu Dhabi - Bangkok on the 19th of February 1995, and

- the study performed during the flight Bangkok - Abu Dhabi - Prague on the 26th of February.

On board flight data for both notes have been available. Let us remind the geographical positions of Prague $\left(50^{\circ} \mathrm{N}, 14^{\circ} \mathrm{E}\right)$, Abu Dhabi $\left(25^{\circ} \mathrm{N}, 54^{\circ} \mathrm{E}\right)$ and Bangkok $\left(13^{\circ} \mathrm{N}, 101^{\circ} \mathrm{E}\right)$. The level of cosmic radiation was at the period of both flights practically the same as during the flight to Montreal (Spurny et al., 1996), about $2 \%$ higher than the average value during all the 1994 year.

\section{Results}

\subsection{NAUSICAA TEPC - counter results}

Flight from Prague to Abu Dhabi had been effected at the constant flight altitude 37000 feet (flight time 5.5 hours); from Abu Dhabi to Bangkok at the same level during the same flight time. The return flight had been effected at the flight level 33000 feet between Bangkok and Abu Dhabi (flight time 6.4 hours), and at three different levels (33000 feet -2.8 hours; 37000 feet -1.1 hours; and 31000 feet - 2.5 hours) between Abu Dhabi and Prague. The measurements with NAUSICAA have been repeated with a 10 minutes reading cycle. While the readings between Abud Dhabi and Bangkok were at the same constant flight level, between Prague and Abu Dhabi they have changed even at the same flight altitude. Typical example is for statistically more reliable low LET component of the radiation on board shown in Figure 1. One can see there that the radiation level decreases when leaving Prague, the most important changes taking place up to Damascus. The same behaviour has been observed for the return flight and it was also observed in our previous work (Reitz et al. Eds, 1993; Spurný and Votočková, 1994). Such behaviour is connected with the influence of the Earth's magnetic field on the ability of cosmic rays to penetrate in the Earths'atmosphere (Reitz, 1993). It is predicted that the decrease of exposure starts at about $3 \mathrm{GV}$ of geomagnetic rigidity (Prague position $\sim 4 \mathrm{GV}$ ) and it is practically finished at about $11 \mathrm{GV}$ (Damascus position $11 \mathrm{GV}$ ) (Reitz, 1993). We tried to analyze this decrease taking into account the data measured for the low LET component. We found that the decrease of exposure level for low LET radiation between Prague and Damascus is characterized by a factor 3 to $4( \pm 15 \%)$ depending on the set of data taken into account.

As far as the lineal energy event spectra are concerned, their general shapes have been similar for all flight altitudes and also similar to the spectra measured previously during Prague - Montreal flights (Spurný et al., 1996). The relative importance of high LET part of spectra has been, however, a little less important 
in equatorial regions. The average quality factor established here is $(1.65 \pm 0,09)$ comparing to $(1.80 \pm 0,07)$ for northern routes. It corresponds well to the prediction that the decrease of exposure due to high LET (neutron) component would be even more important than due to low LET component (Reitz, 1993).

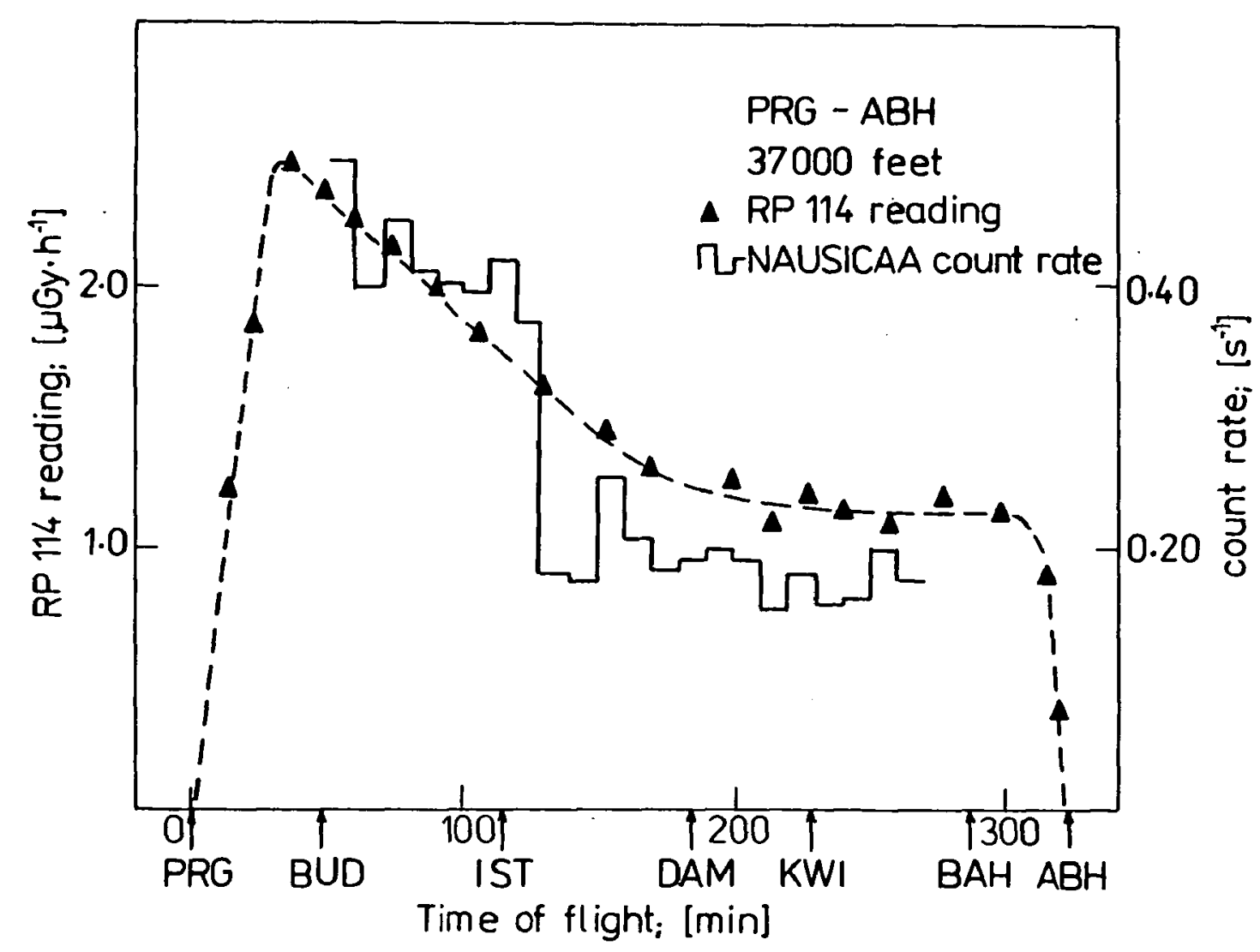

Fig. 1 - The values of some low LET radiation characteristics as a function of the time of flight between Prague and Abu Dhabi.

Les valeurs des quelques caractéristiques dosimétriques du composant TLE bas en fonction du temps de vol entre Prague et Abu Dhabi. (PRG) Prague; (BUD) Budapest; (IST) Istanbul; (DAM) Damascus; (KWI) Kuwait; (BAH) Bahrajn; (ABH) Abu Dhabi.

Average level of dosimetric rate values as measured with NAUSICAATEPC counter are for all four flights presented in Table I.

\subsection{Exposure levels measured with other instruments}

Also the results of measurements with other active instruments have shown the same tendencies, i.e. the decrease of the rate values between Prague and Damascus, and the constancy of them afterwards up to Bangkok; at the constant flight level, of course. The values averaged over each of the four flights are for some of dosimetric characteristics presented in Table II, together with values deduced from NAUSICAA results. 
TABLE 1

Dosimetric characteristics of on-board radiation fields as measured with NAUSICAA-TEPC

Caractéristiques dosimétriques du champ de radiation mesurées avec le CPET NAUSICAA à bord d'avions de ligne

\begin{tabular}{|c|c|c|c|c|c|}
\hline \multirow{2}{*}{\multicolumn{2}{|c|}{ Flight $\quad$ Alritude }} & \multicolumn{4}{|c|}{ Average dosimetrie characterisfies } \\
\hline & & $\begin{array}{l}\text { Dose } \\
\text { How }_{\text {(III) }} \\
\end{array}$ & thate & 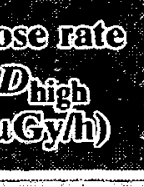 & $\begin{array}{l}\text { Count rate } \\
\left(\mathbf{s}^{-3}\right)\end{array}$ \\
\hline PRG-ABH & 11.3 & $1.62(3)$ & 1.91 & 0.269 & 0.292 \\
\hline $\mathrm{ABH}-\mathrm{PRG}$ & $10.0^{(2)}$ & 1.27 & 1.00 & 0.188 & 0.215 \\
\hline ABH-BKK & 11.3 & 0.914 & 0.842 & 0.133 & 0.164 \\
\hline BKK-ABH & 10.1 & 0.716 & 0.524 & 0.098 & 0.126 \\
\hline
\end{tabular}

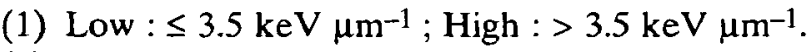

(2) Average value from three levels $(10.1 ; 11.3 ;$ resp. $9.5 \mathrm{~km})$.

(3) For PRG-ABH and ABH-PRG the values changed during the flight; for ABH-BKK and $\mathrm{BKK}-\mathrm{ABH}$ flightthe typical standard deviations were about $5 \%$ for $H_{\text {low }}, D_{\text {high }}$ and the count rate, about $10 \%$ for $H_{\text {high }}$ (see also Spurný et al., (1996)).

TABLE II

Direct average readings of active measuring instruments Moyenne des mesures réalisées avec des détecteurs actifs

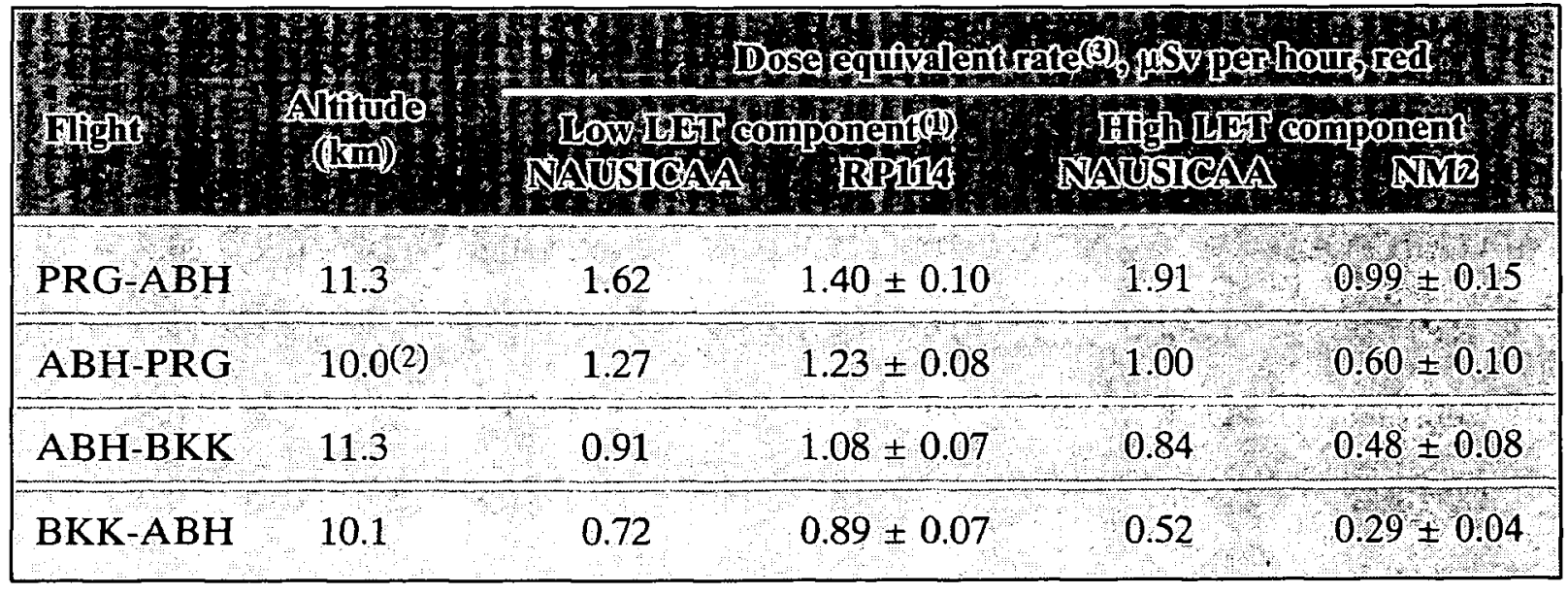

(1), (2), (3) see Table I. 
One can see there that:

- the ratio of the reading of low LET component measuring instruments is equal to $(0.96 \pm 0.14)$, i.e. small overreading of NAUSICAA observed previously is not confirmed (Spurný et al., 1996);

- the ratio of the reading of high LET (neutron) component measurements is equal to $(1.8 \pm 0.1)$, i.e. is practically the same as observed at northern routes $(2.1 \pm 0.3)$ (Spurný et al., 1996).

\subsection{Integral values of exposure}

Other detector tested provided directly the apparent integral values of exposure; flight profiles known have permitted to estimate the apparent dose equivalents from rate values measured by active instruments. The apparent values (i.e. in $H^{*}(10)$ of reference radiation) have been converted to the $H^{*}(10)$ due to on board radiation using a correction factor of 1.25 for low LET radiation measuring instruments other than NAUSICAA, using a correction factor of 2.00 for high LET (neutron) measuring instruments, again others than NAUSICAA. The values of these factors are explained in a previous work (Spurný et al., 1996). The results obtained are presented in Table III.

TABLE III

Integral values of the ambient equivalent - best estimate using the correction factors mentioned

Valeurs intégrées de l'équivalent de dose ambiant - meilleure estimation en utilisant les facteurs de correction mentionnés

\begin{tabular}{|c|c|c|c|c|c|c|}
\hline \multicolumn{2}{|c|}{ Dosimetric Compo } & \multicolumn{4}{|c|}{ HE(10), $\mathrm{CSV}_{2}$ for the linght } & Total \\
\hline NAUSICAA & & $9.4 \pm 1.4$ & $4.1 \pm 0.8$ & $3.1 \pm 0.5$ & $5.8 \pm 1.0$ & $22.4 \pm 3.7$ \\
\hline NM2 & High & $9.7 \pm 1.5$ & $4.7 \pm 0.7$ & $3.4 \pm 0.5$ & $7.0 \pm 1.1$ & $24.8 \pm 3.8$ \\
\hline BDND PDN & LET & $7.1 \pm 1.5$ & $2.9 \pm 1.0$ & $3.8 \pm 1.6$ & $9.5 \pm 2.5$ & $23.3 \pm 6.6$ \\
\hline BD100R & & $8.5 \pm 1.7$ & $5.0 \pm 1.3$ & $4.0 \pm 1.6$ & $7.0 \pm 1.5$ & $24.5 \pm 6.1$ \\
\hline NAUSICAA & & $7.9 \pm 0.8$ & $4.5 \pm 0.7$ & $4.2 \pm 0.6$ & $7.4 \pm 0.9$ & $24.0 \pm 3.0$ \\
\hline RP114 & Low & $8.6 \pm 0.9$ & $6.6 \pm 1.0$ & $5.2 \pm 0.8$ & $8.9 \pm 1.3$ & $29.3 \pm 4.0$ \\
\hline D222 & LET & $9.4 \pm 1.4$ & $6.3 \pm 1.2$ & $5.6 \pm 1.2$ & $9.2 \pm 1.3$ & $30.5 \pm 5.1$ \\
\hline DMC90 & & $6.2 \pm 1.6$ & $4.1 \pm 0.8$ & $3.7 \pm 0.8$ & $5.3 \pm 0.8$ & $19.3 \pm 4.0$ \\
\hline TLD's & & - & - & - & - & $30 \pm 10$ \\
\hline
\end{tabular}


One can see in Table III that:

a) There is a reasonable agreement of most of the values read and/or corrected in the case of high LET (neutron) radiation. It should be however stated that the accuracy of most of them is not the best. This is reasonable because the signal for some of detectors is already comparable with the electronic background (NM2, NAUSICAA); for other ones (BDND's), it is statistically not too reliable (10 to 30 events at all).

b) The agreement is less satisfactory for low LET radiation devices and detectors. First, as already mentioned, the DMC90 readings are regularly lower, probably due to differences in energy transfer coefficients (Spurny et al., 1996). The secondly, the readings of RP114 and D222 are, after applying the correction factor of 1.25 , regularly higher than NAUSICAA results. It is not evident why this factor should not be the same for equatorial regions as for northern routes (Spurný et al., 1996). Nevertheless, it should be stressed that the accuracy of all results is, as for high LET and for the same reasons, also not the best.

\section{Conclusions}

The general conclusions from the analysis of data are:

1) The influence of geographical position on the level of aircraft exposure is important. As an example, it is possible to compare the integral dose equivalent during the flights Montreal - Prague and Bangkok - Abu Dhabi. The time of flight was practically the same, the average flight altitude was $10.5 \mathrm{~km}$ for the northern route, $10.1 \mathrm{~km}$ for the equatorial one. However the low LET dose equivalent was about 4 times higher for northern route, and high LET part even 5 times. A slightly smaller difference can be seen also when comparing the northern route levels to Prague - Abu Dhabi flights (about two times for rate values).

2) It should be stressed that this influence is not equally distributed over the world. When one analyzes the geometric rigidity map (see Fig. 2), the "northern" situation (i.e. with the rigidity below about $4 \mathrm{GV}$ ) is typical for Northern America, Europe, typical trans-Atlantic and polar routes. On the other hand Africa, The Southern America and the most populated areas of Asia are closer tot the "equatorial" situation.

3) As far as the characteristics of the exposure level in general are concerned, the conclusions concerning the influence of other factors (altitude, solar cycle influence, variations of exposure for the same route) formulated in our previous works are also valid. It should be added that all these factors are due to much lower exposure levels, which are much less important for the total exposure of aircraft members. 


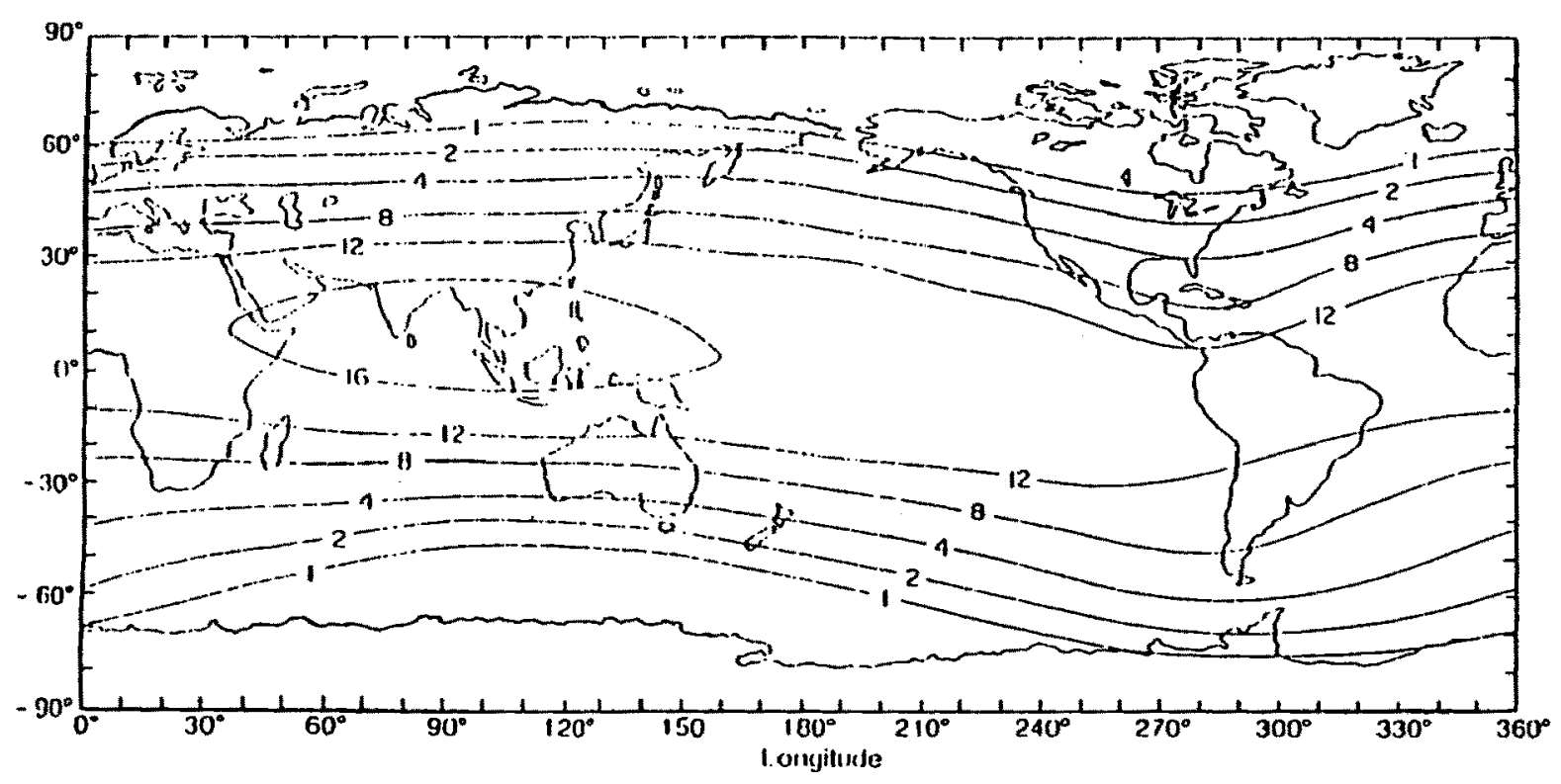

Fig. 2 - Vertical cut-off rigidity calculated for an altitude of $20 \mathrm{~km}$ (Reitz, 1993). Rigidité verticale de coupure à l'altitude de $20 \mathrm{~km}$ (reproduit de Reitz, 1993).

\section{RÉFÉRENCES}

Anderson I.O., Braun J.A. (1964) A Neutron Rem Counter. Nukleonik 6, 237-241.

Bousset P., Nguyen V.D. et al. (1992) Description de l'instrument NAUSICAA conçu pour effectuer des mesures instantanées de H.D. et du spectre de T.E.L. en champs complexes. In: IRPA, Montréal, May 1992, pp. 463-466.

Guelev M.G., Mischev I.T., Burgkhardt B., Piesch E. (1994) A Two Element CaSO 4 :Dy Dosemeter for Environmental Monitoring. Radiat. Prot. Dosim. 51, 35-40.

Höfert M., Stevenson G.S. (1994) The CERN-CEC High Energy Reference Field Facility. In: the 8th Int. Conf. on Rad. Shielding, Arlington, Texas, April 1994.

ICRP (1991), ICRP Publication 60. Recommendations: Annals of ICRP 21, No. 1-3.

ING H. (1991) Bubble Technology Industries Report. Chalk River.

Nguyen V.D., Luccioni C., Parmentier N. (1985) Average Quality Factor and Dose Equivalent Meter Based on Microdosimetry Technique, Radiat. Prot. Dosim. 10, 277-288. Radiation Exposures of Civil Aircrews (1993) (G. Reitz, H. Schnuer, K. Shaw Eds.) Special Issue of Radiat. Prot. Dosim. 48, No 1.

Radiometer RP114 (1992) Description Manual, ZMA Ostrov nad Ohří, Czech Republic. Reitz G. (1993) Radiation Environment in the Stratosphere. Radiat. Prot. Dosim. 48, 5-20. Spurný F., Turek K., Alberts W.G. (1993) On the Optimization of the Etching of CR39 as Fast Neutron Dosemeter. Nucl. Tracks Radiat. Measur. 21, 299-302.

Spurný F., Votočková I. (1994) Radiation Exposure of Aircraft and Passengers During Some CSA Commercial Flights. In: Proc. 26. Jahrestangung des Fachverbandes für Strahlenschutz, Karlsruhe 1994, vol. II, 549-553.

Spurný F., Votočková I., Bottollier-Depois J.F. (1996) Aircrew Exposure on Board a Subsonic Aircraft Studied with Complex Dosimetric Sets. Radioprotection 31, 91-100. 